\title{
Reactive scheduling based on actual logistics data by applying simulation-based optimization

\author{
Kamil Szczesny ${ }^{*}$ and Markus König
}

\begin{abstract}
Background: A reasonable management and monitoring of construction projects requires accurate construction schedules. Accuracy depends highly on availability of reliable actual logistics data. Such data contain information about available material, equipment, personnel, updated delivery dates, and other data on site conditions. However, such data is often associated with different types of uncertainties due to infrequent collections, varying transport times, or manual assessments. Nonetheless, consideration of these uncertainties is important for evaluating actual data regarding their impact on the overall construction progress. Currently, the integration of such data into construction schedules is a time-consuming, manual and, thus, error-prone process. Therefore, in practice schedules are not updated as often as they should be.
\end{abstract}

Methods: To ease the handling of actual data and their integration into construction schedules, a reactive construction scheduling approach is presented. The approach is structured into four successive steps. To evaluate and systematically analyze uncertain actual data, fuzzy set theory and a-cut method are incorporated. Thus, actual data can be integrated into discrete-event simulation models. These models are used to perform simulation-based sensitivity analyzes, which evaluate impacts on construction schedules. As a result, an actual schedule is generated, such that a target-actual schedule comparison can be performed. If significant deviations or problems are identified, adaption is necessary and a new schedule needs to be generated. Thereby, different restrictions on the target schedule, such as contracted delivery dates, milestones or resource allocation must be considered. To perform this required adaption simulation-based optimization is utilized.

Results: To validate the method and show its advantages, an initial construction schedule example is created. The example is extended to incorporate uncertain actual logistics data. The proposed method shows how efficient actual data can be analyzed to update construction schedules. Further, the results show a competitive adaption of invalid construction schedules, such that contracted milestones, or other project objectives can be achieved.

Conclusion: The presented reactive construction scheduling method has the ability to improve current treatment of uncertain actual logistics data. This helps construction project managers to improve the management and monitoring of construction projects by reducing the time-consuming, error-prone process of updating inconsistent schedules.

Keywords: Reactive construction scheduling; Schedule adaptation; Simulation-based optimization

\section{Introduction}

The efficient execution of construction projects depends highly on the accuracy of the underlying construction schedules. Here, construction scheduling means to sequence relevant activities based on certain interdependencies and resource availability. Finally, a schedule defines the starting and finishing time of each construction activity as

\footnotetext{
* Correspondence: kamil.szczesny@rub.de

Department of Civil and Environmental Engineering, Ruhr-Universität Bochum, Universitätsstraße 150, Bochum 44801, Germany
}

well as the allocated resources needed for each activity. For project managers, such detailed schedules are the main basis to monitor the activities on construction sites. Due to planning modifications, construction delays, or unforeseen events, schedules are often not up-to-date and must be continuously adapted. However, in practice schedules are not updated as often as they should be. Furthermore, construction schedules often have to be modified due to delays or disturbances of logistics processes. In consequence, actual information about the current state of the construction

\section{实 Springer}

(c) 2015 Szczesny and König. This is an Open Access article distributed under the terms of the Creative Commons Attribution License (http://creativecommons.org/licenses/by/4.0), which permits unrestricted use, distribution, and reproduction in any medium, provided the original work is properly credited. 
progress needs to be collected. Actual logistics data contain information about available material, equipment and personnel as well as updated delivery dates and other data on site conditions. The quality of construction schedules highly depends on the availability of reliable actual data. However, actual data is often associated with different types of uncertainties due to infrequent collections, varying transport times, or manual assessments by engineers. Considering these uncertainties is very important for evaluating actual data regarding their impact on the overall construction progress. After analyzing the actual data, an updated or so-called actual schedule can be defined. This actual schedule should be compared to the target schedule to detect significant deviations. If crucial delays are identified, the existing target schedule needs to be adapted. This procedure is known as reactive scheduling. Currently, the adaptation of construction schedules is a manual, time consuming, error prone, and therefore poorly supported process (Song and Eldin 2012). In practice, there exists a high demand for efficient and userfriendly concepts, which can integrate and evaluate actual data as well as compare and update schedules.

In the last few years, discrete-event simulations have increasingly supported the specification of realistic and efficient construction schedules. With the help of discrete-event simulations, it is possible to analyze construction activities and complex interdependencies under varying project conditions (AbouRizk 2010). Project modifications or construction delays can be evaluated by changing certain input parameters or by adding additional constrains. Another advantage of the application of discrete-event simulations is the possibility to couple them with optimization methods to generate good schedules. In this case, sequences and resource allocations are varied to find efficient schedules regarding different objectives, including short construction times, low costs, and high resource utilization. Updating a construction schedule can be defined as an optimization problem to find a new schedule considering new information by minimizing the deviations from existing project goals. In addition, so-called target schedule constraints need to be considered, such as fixed material delivery dates, on-site resources, contracted milestones and established sequences.

This paper presents a novel and holistic framework for reactive construction scheduling based on actual data by applying simulation-based optimization. The focus lays on actual logistics data. However, other actual data can also be modeled and be investigated by using this approach. The proposed framework comprises three main contributions, which are not found in this combination in previous research:

- Preparation of uncertain actual logistics data

- Analyzing actual data using construction simulation
- Modeling of target schedule constraints and adapting target schedules by applying simulationbased optimization.

In consequence, with the help of the proposed framework, project managers can monitor construction work more efficiently based on updated and more realistic schedules.

\section{Background}

In practice, some construction delays may have their origin in the unavailability of material, equipment, or personnel. Some of these delays can be identified proactively by analyzing the actual delivery states. Other delays are the result of unforeseen events like equipment breakdowns or lacking personnel. In the manufacturing industry, the acquisition of actual data is often performed by Auto-ID techniques such as biometrics or RFID. Due to fixed production lines, established and well-monitored supply chains, identifiable resources, and detailed schedules the recorded actual data can be clearly associated to the production activities. Furthermore, the measured data often contains only marginal uncertainties. Consequently, actual data can be directly used to update the planned schedule (Hotz et al. 2006). In contrast, in civil engineering several concepts regarding the acquisition of actual data by Auto-ID techniques were proposed just recently. Only a few early applications were implemented in practice. For example, in Cho et al. (2011) and Yin et al. (2009) the authors propose RFID-based production management systems. The former investigates vertical resource transports while the latter one performs a construction yard tracking. In Kim et al. (2009) and Ren et al. (2011) RFID-based goods inward inspections are developed. RFID-based supply chain control and management system for construction projects is developed in Wang et al. (2007). In Ergen et al. (2007), the authors propose a concept regarding intelligent building components. These components are capable of holding information about their states, or assembly guide and maintenance information. In order to assess the progress of construction activities, an automated progress control using laser-scanning technology is presented in Zhang and Arditi (2013). Laser-scanning technology is utilized to overcome unsatisfactory results by employing image processing and other techniques. Their system is able to assess progress control with minimum human input. In Cai et al. (2014), Dzeng et al. (2014), and Montaser and Moselhi (2014) different methodologies for RFID-based location and tracking are presented. These approaches enable the acquisition of data on a construction project status in almost realtime and detect the locations of workers and materials with very high accuracy. However, none of these researches 
considers the evaluation of uncertainties and their impact on schedules.

Few researchers are dealing with the adaption of target construction schedules in case of infeasibility or nonoptimality due to disturbances. In Koo et al. (2007), a formal identification and re-sequencing process is presented. This approach supports fast development of sequencing alternatives in construction schedules. The approach is based on CPM without considering resources or working shifts. In Liu and Shih (2009), another rescheduling approach is introduced which is based on Constraint Programming. Two rescheduling methods are presented: the complete regeneration and the partial rescheduling. However, these rescheduling approaches are based on mathematical models rather than simulation models and not applicable for the proposed approach in this paper.

The utilization of discrete-event simulation models is an established methodology for the analysis and planning of construction activities. CYCLONE by Halpin (1977), STROBOSCOPE by Martinez and Ioannou (1994) and Simphony by Hajjar and AbouRizk (1999) are the first and important steps in the context of construction simulation. Domain specific construction activities, resource requirements, and technological dependencies can be described by applying different modeling concepts. These simulation frameworks are more flexible which allows the creation of more realistic simulation models. For example, special-purpose simulation-modeling tools are developed in Martinez (1998) and Ruwanpura and AbouRizk (2001). Nevertheless, the effort to model realistic simulation models is very high and these simulation frameworks always model an explicit process chain. According to $\mathrm{Wu}$ et al. (2010) most construction processes consist of dynamic and spontaneous sequences of activities. Because of this, simulation is not often applied in practice. Therefore, recent research is investigating model driven simulation modeling. With the help of building information models (BIM) and knowledge-based methods, semi-automatic model generation can be implemented (Wu et al. 2010; Xu et al. 2003). Moreover, by combining the Constraint Satisfaction Approach with discrete-event simulations, it is possible to guarantee that only valid construction schedules will be generated (Beißert et al. 2007).

Regarding the optimization of real construction schedules, several research approaches exist. For detailed literature reviews, we refer to Hartmann and Kolisch (2006) and Liao et al. (2011). Many optimization approaches utilizing genetic algorithms are proposed. To name only a few we refer to Leu and Yang (1999), Chen and Weng (2009), Ghoddousi et al. (2013) and Esthehardian et al. (2009). These approaches contributed to resource allocation and resource leveling. In order to tackle multi-mode resource constraint project scheduling problems (MRCPSP) by considering resource allocation and resource leveling simultaneously, the utilization of the Non-dominated Sorting Genetic Algorithm (NSGA II) (Deb et al. 2002) has been proved successful. In particular, Esthehardian et al. (2009) applied fuzzy numbers in order to model uncertainties in activities concerning execution time and cost. A different optimization approach by Said and El-Rayes (2014) provides a holistic BIM-based framework to optimize material supply and site decisions to minimize total logistics costs. However, these optimization approaches neither applied actual logistics data nor simulation models regarding reactive construction scheduling.

To our best knowledge, there is no research work available, which deals with reactive construction scheduling using actual logistics data. Therefore, we purpose a novel and holistic concept for reactive construction scheduling for controlling and updating construction schedules.

\section{Methods}

\section{Reactive construction scheduling methodology}

In this paper, the adaptation of construction schedules is based on actual logistics data. The adaption is a crucial part in the context of reactive scheduling. Reactive scheduling means that actual data is considered for automated controlling and updating of construction schedules. Figure 1 illustrates a schematic overview of this approach.

The concept consists of four steps. First, the acquisition and preparation of actual logistics data is performed. The accuracy and inherent uncertainty depends on the location where the actual data is collected. In addition, manual assessments by engineers must be taken into account. In the next step, the prepared data is integrated into the construction schedule. For that purpose, a simulation model is created which represents the target schedule including all activities, resources and restrictions. Actual data is defined as additional constraints for the involved activities. A simulation-based analysis is performed to investigate how the actual logistics data affects the schedule. Based on the target-actual comparison a decision needs to be made, if an adaption of the target schedule is necessary. In the last step, the planned schedule can be updated, if crucial delays or other significant deviations were detected. Thereby, the adaptation should be as much as necessary and as little as possible. That means that execution sequences, resource allocations or the planning should be retained unchanged.

\section{Preparation of uncertain actual logistics data}

Several techniques exist to model and analyze uncertainties in model parameters, such as actual data. Often, probability based methods are applied to define reasonable probability distributions. In order to define a reasonable probability distribution, historical data are required. To integrate such probability distribution functions into simulation models, a very common technique is to apply Monte 


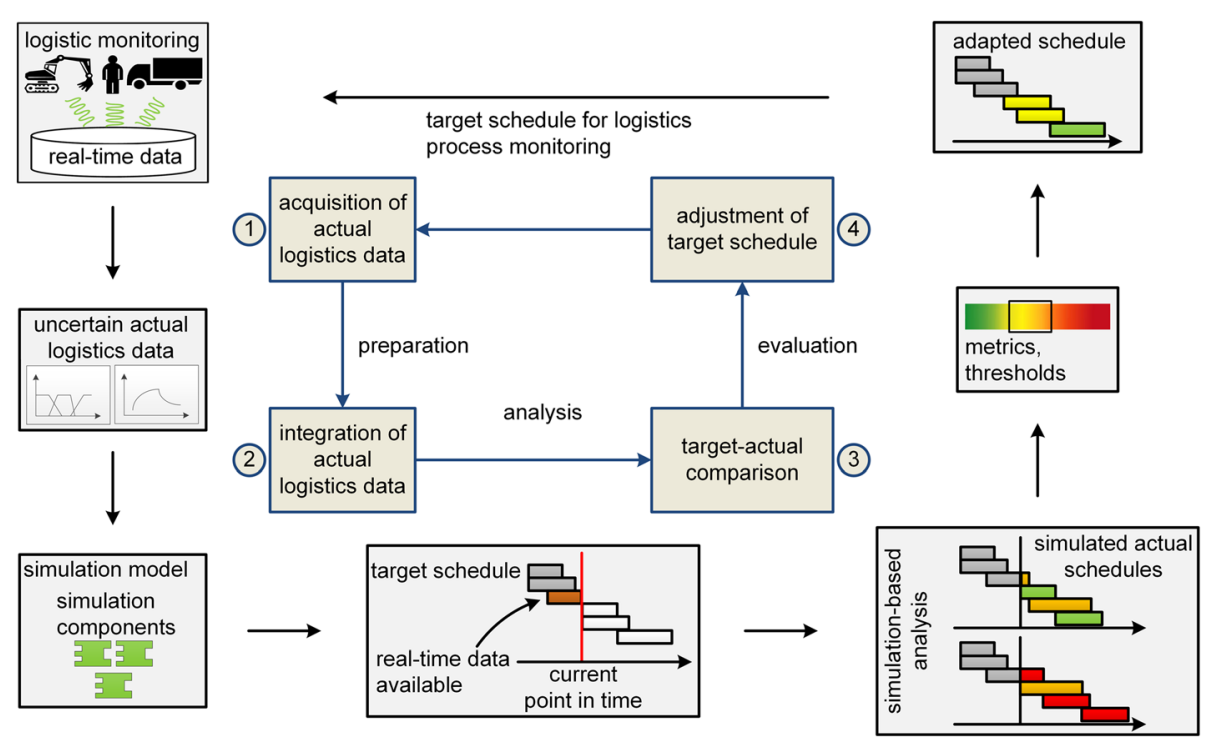

Fig. 1 Schematic overview of the reactive construction scheduling approach

Carlo simulations. Monte Carlo simulation handles uncertain input parameters as random variables based on given probability distributions. However, for construction projects historical data are often not available.

In cases when only imprecise data or assessments are available, fuzzy modeling based on the fuzzy set theory of Zadeh (1965) can be used. The fuzzy set theory enables a formal description of uncertainty and imprecise statements. The essential concept of this theory is the definition of sets that are based on multi-valued logic rather than the classical Boolean or two-valued logic. According to the Boolean set theory, the membership of an element is described by exactly two crisp values. Either the element is member of the set or it is not. Contrary, the fuzzy set theory extends the membership of an element by introducing a membership function $\mu(x)$ with $\mu(x) \in[0,1]$. Then, a fuzzy set $\mathrm{X}$ is a set of pairs $(x, \mu(x))$ with $x \in \mathbb{R}$ with associated values of a membership function $\mu(x) \in[0,1]$. A membership function represents the grade of membership of $\mathrm{x}$ in $\mathrm{X}$. Thus, $\mu(x)=0$ means that $\mathrm{x}$ does not belong to the set $\mathrm{X}$. As an example, the statement "Delivery of the precast concrete element will be in approximately five days" can be modeled by a fuzzy set as depicted in Fig. 2. Here, the statement "approximately five days" is modeled by a triangular fuzzy set $\mathrm{X}$, which is given by a triangular function with the values three, five, and seven days, where five days means complete membership of the set X.

Similar to analyzing a distribution function using a Monte Carlo simulation, fuzzy sets can be investigated by using a fuzzy $\alpha$-cut analysis (Abebe et al. 2000). An $\alpha$-cut represents the degree of certainty for a given statement or, in other words, the reliability of the fuzzy estimation. Accordingly, the example in Fig. 2 implies that an $\alpha$-cut value of 1.0 represents a $100 \%$ certainty that the material delivery will be in exactly in five days, whereas an $\alpha$-cut of 0.5 implies that, the material delivery will be in four through six days. A complete analysis of the fuzzy sets requires an $\alpha$-cut for each fuzzy set. Each $\alpha$-cut represents a certain interval, with a minimum and a maximum value. Within the range of the minimal and maximal interval value, a fixed amount of equally distributed samples is derived. Every single derived sample value is used as one discrete experiment parameter. As with the Monte Carlo simulation approach, the last step performs a statistical analysis of the various results. According to Abebe et al. (2000) and Hanss (2005), an $\alpha$-cut analysis approach requires considerably less experiments than the Monte Carlo approach in order to achieve at least the same quality of results. Another advantage is the consideration of

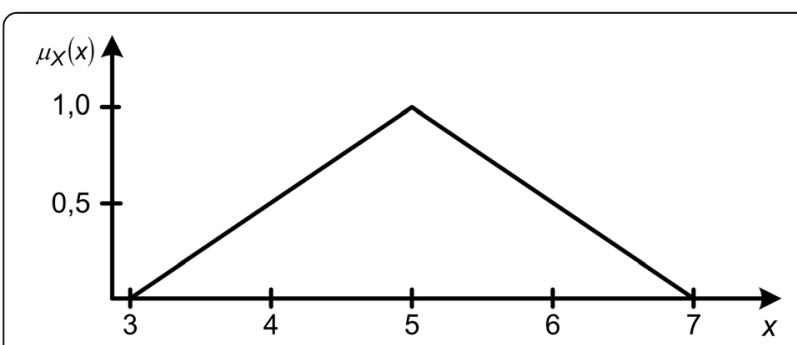

Fig. 2 Fuzzy set for the statement "Delivery of the pre-cast concrete element will be in approximately five days" 
subjective estimations by declaring a level of reliability based on the $\alpha$-cut (Kulejewski 2011).

Regarding civil engineering, the acquisition of actual logistics data is infrequent. Actually, the data recording is performed only for certain points in time or special locations. A typical example for this is the manufacturing and delivery of precast concrete parts, e.g. columns or walls. For such parts, the corresponding actual data can be recorded at the production beginning, when the part is finished, during goods leaving the precast plant, or during intermediate bearing or transportation (cf. Fig. 3).

Very often, it is impossible to specify the duration between two data recordings accurately. Therefore, fuzzybased statements are well suited to describe such data, which additionally involves a degree of certainty. In order to describe fuzzy-based durations between several acquisition time points, linguistic statements are mapped to fuzzy sets. For instance, linguistic statements consist of terms like "about" or "approximately between". Regarding the level of detail, in civil engineering it is sufficient to consider days or half-days. This is because more detailed planning is very often impossible. The definition of reasonable fuzzy sets is extremely important. If possible, data based on experience should be considered. Especially, for very long time durations, e.g. "approximately between 4 to 8 weeks" the extreme values should be appropriate. When more than one actual data is available during the logistic chain, it is necessary to sum them up with fuzzy sets. For this, fuzzy set arithmetic is applied. A short summary of basic interval arithmetic can be found in Buckley and Eslami (2002).

Let $K=[a, b]$ and $L=[c, d]$ be two closed intervals. Then

$$
K+L=\{x+y \mid x \in K, y \in L\}
$$

According to equation 1, the following can be summarized:

$$
[a, b]+[c, d]=[a+c, b+d]
$$

Regarding fuzzy set arithmetic, $\alpha$-cuts of fuzzy sets are always closed and bounded intervals. Assume $\bar{M}$ and $\bar{N}$ are two fuzzy sets, then let $\overline{\mathrm{M}}[\alpha]=\left[\mathrm{m}_{1}(\alpha), m_{2}(\alpha)\right]$ and $\overline{\mathrm{N}}[\alpha]=\left[n_{1}(\alpha), n_{2}(\alpha)\right]$ for $0 \leq \alpha \leq 1$. Based on this, fuzzy set arithmetic can be defined in terms of their $\alpha$-cuts (cf. Buckley and Eslami 2002). If $\overline{\mathrm{P}}[\alpha]=\overline{\mathrm{M}}[\alpha]+\overline{\mathrm{N}}[\alpha]$, then $\overline{\mathrm{P}}[\alpha]=\left[m_{1}(\alpha)+n_{1}(\alpha), m_{2}(\alpha)+n_{2}(\alpha)\right]$. If various fuzzy sets need to be evaluated into one resulting set, the presented addition rule can be applied. This operation can also be used when different degrees of certainty have to be taken into account for two or more fuzzy set. In other words $\alpha$ of $M \neq \alpha$ of $N$. Figure 4 depicts an example. Here, $\mathrm{M}$ ("about 2 days") with $\alpha=0.6$ and $\mathrm{N}$ ("approximately between 3 to 5 days") with $\alpha=0.25$ are summed up. The interval at level 0.6 is applied as long as N's interval reaches the same level. The result is a fuzzy set that corresponds to "approximately between 3.1 to 8.9 days".

\section{Analyzing actual data using construction simulation}

The basis for the reactive adaptation of construction schedules is the application of discrete-event simulation. Discrete-event simulation is used to generate constructions schedules considering several types of constraints, such as precedence relationships, varying resources, shift calendars, and required material. To enable a flexible definition and integration of different constraints, so-called constraint-based simulations have been developed (Beißert et al. 2007). Constraint-based simulation is an extended discrete-event simulation approach. Each time an event occurs, all constraints

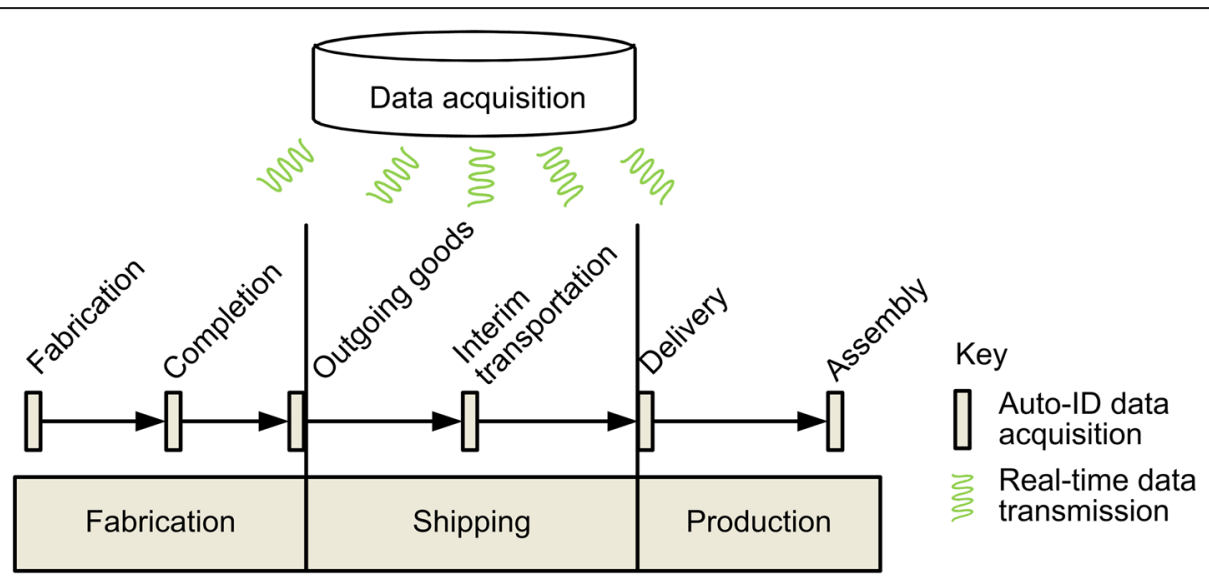

Fig. 3 Schematic construction supply chain with time points and locations for data acquisition 


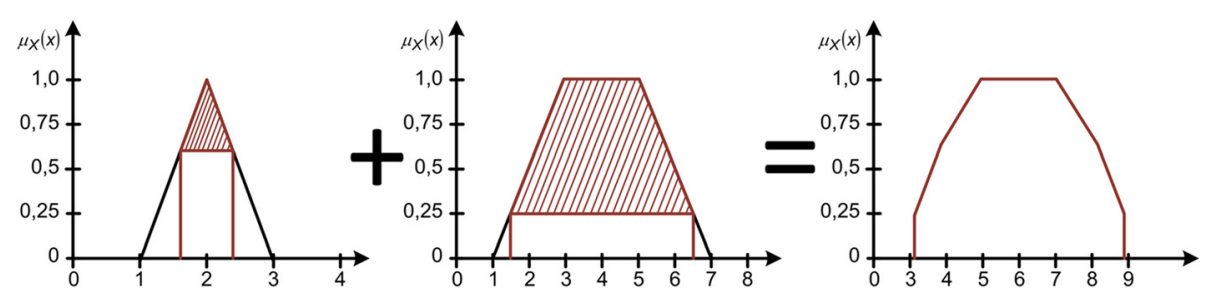

Fig. 4 Fuzzy set arithmetic example demonstrates how two fuzzy sets with different degrees of certainty are calculated for the addition case

are checked to identify which activity can be scheduled next (cf. Fig. 5).

Generally, hard and soft constraints can be defined and checked. Typically, hard constraints are precedence restrictions, resource requirements, earliest starting times or fixed time windows. Meaningful conditions, like preferred staring times and resource allocations, delivery dates, or established execution sequences, are modeled as soft constraints. Soft constraints do not have to be satisfied completely. Solely, a fulfillment degree is calculated to evaluate the satisfaction. In this paper, all soft constraints are defined based on weighted or k-weighted constraints. If weighted or k-weighted constraints cannot be completely fulfilled, the weights can be used to calculate so-called violation cost factors. For k-weighted constraints, the threshold $\mathrm{k}$ specifies a lower and/or upper bound for the calculation of the cost factor (cf. Fig. 6). Costs factors can represent monetary costs or abstract costs. Consequently, different schedules can be analyzed regarding their fulfillment by calculating the schedule's total cost factor due to constraint violations.

In order to reflect the current state of the construction project the simulation model needs to be updated. Activities that are already completed are no longer considered. Furthermore, the activities that have already started will be continued. However, the allocated resources can be increased to complete the activity in a shorter time. The presented paper does not cover how to collect the actual status of construction. Different techniques from manual inspection to automated approaches using laser-scanning, Auto-ID systems or images are possible. In the end, information about the progress of each activity must be defined. Within the constraint-based simulation, the actual status of construction is considered as follows. Already finished activities are removed from the simulation model. Currently running activities get a higher priority and all precedence relationships are removed. Furthermore, the remaining duration needs to be adapted based on the

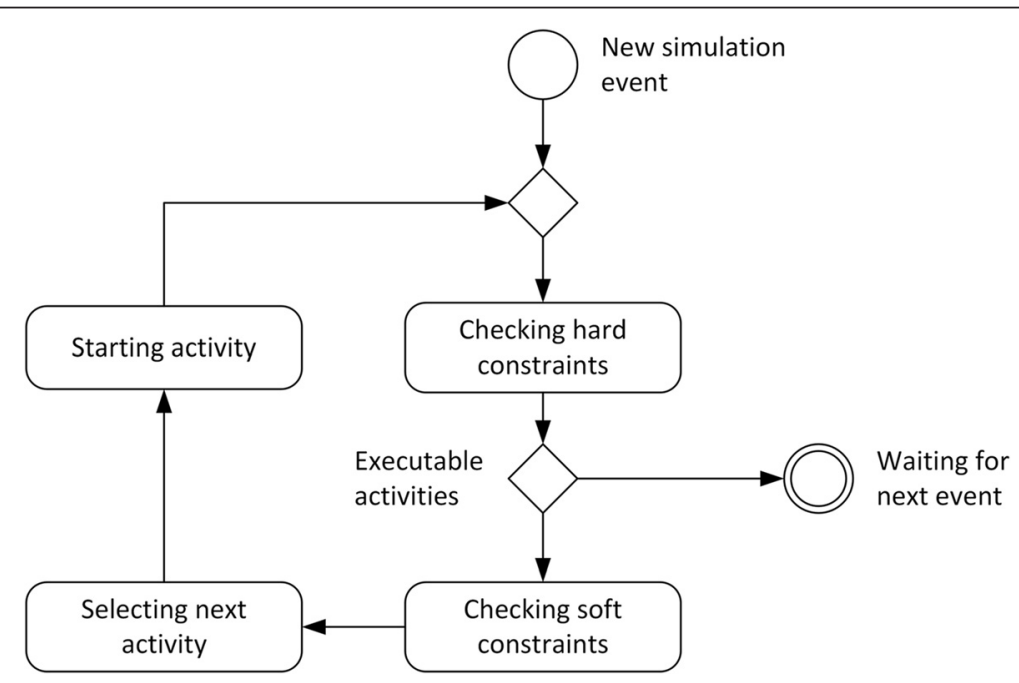

Fig. 5 Constraint-based simulation approach. General iterative process flow of the constraint-based approach is the following: A new simulation event arrives at the entry point and triggers off the evaluation of hard constraint feasibility for to-be scheduled activities. Afterwards, a decision is made, whether any activity exists whose hard constraints are fulfilled. If no such activity exists, then the iteration exits and the simulation engine processes the next simulation event. If at least one such activity exists, then the soft constraints for every single activity are evaluated. The activity with the lowest soft constraint violation is chosen to be scheduled next. Afterwards, the evaluation loop repeats again to evaluate hard constraints for to-be scheduled activities. This step is necessary because the previous scheduled activity may have blocked resources that were available during the first evaluation in this loop 


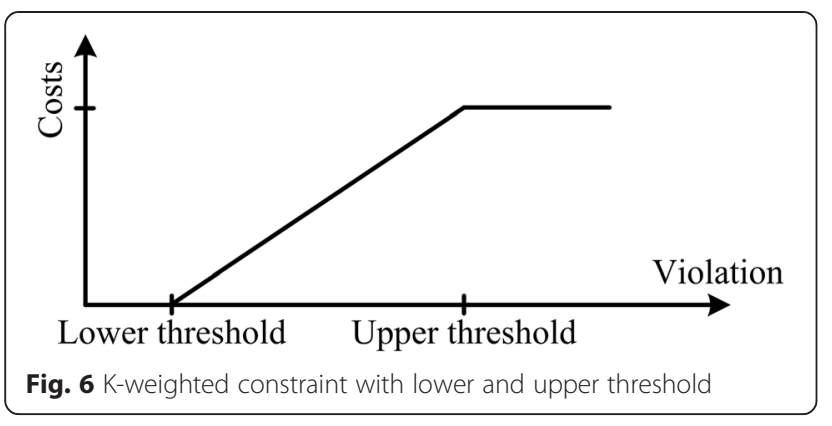

actual progress. If actual information regarding resource assignments of running activities is available, then the same resources should be used again in scope of the schedule adaptation. Of course, this is only possible if the resources are still available.

In this paper, the integration of actual logistics data is highlighted. As mentioned before, actual logistics data contain information about available labor resources, material, and equipment as well as updated delivery. These actual data could have some effects on the execution of certain construction activities. For example, if material is not available the execution of related activities cannot be started. In this research, actual logistics data always results in so-called availability constraints. Availability constraints apply to certain objects, such as labor resources, material, equipment, or spaces. Consequently, the availability can be restricted regarding a certain time window. For each object affected by actual data, an availability constraint is incorporated into the simulation model. After this integration part finishes, the simulation-based analysis takes place. With the help of several simulation experiments, the impact of the actual logistics data on the target schedule is analyzed. The analysis results in an actual schedule. This schedule consists of construction activities with their starting and finishing times according to the uncertain actual logistics data. Additionally, the schedule includes the mean and standard deviation of these times. A target-actual construction schedule comparison uses this actual schedule. The comparison procedure compares the activity's starting and finishing times. During this procedure, certain threshold values may be applied. This means that it is legal to tolerate a difference in the starting time of an activity, when this difference is small regarding the target schedule. However, when a given threshold is exceeded, then a re-scheduling might be required. In addition, different threshold values for different project objectives can be applied. For instance, violations to project milestones are not tolerable and could demand a re-scheduling in order to achieve the defined milestones. In many cases, an adaption of the target construction schedule is required if the comparison shows a significant deviation and important project goals cannot longer be maintained.

\section{Modeling of target schedule constraints}

Because the adaptation should be as large as necessary and as little as possible, additional scheduling restrictions based on general project goals and the target schedule should be defined. In the following, some typical restrictions of construction projects are highlighted. Obviously, this listing is not exhaustive. In some cases, additional project specific constraints should be considered. However, additional target schedule constraints can be defined in the same way.

\section{Delivery dates}

Frequently, short-term modifications of some delivery dates are not possible or very costly. This is particularly true if the delivery is scheduled within a few days. For example if the delivery and the just-in-time placement of pre-casted elements is scheduled in five days, if no storage areas are available on the construction site, and if the supplier can only guarantee available means of transport in the following five to seven days, then the activities for placing the pre-casted elements should not be postponed substantially. Time windows in which certain activities should be scheduled can be modeled by delivery date constraints. These delivery date constraints are represented by k-weighted soft constraints. That means, if an activity is scheduled outside the bounds of the time window, additional costs will occur. However, when a certain threshold $\mathrm{k}$ (e.g., three days) is exceeded, then these soft constraints behave like hard constraints, i.e. the soft constraint remains unfulfilled.

\section{Temporal equipment}

Another restriction is the assignment of temporal equipment, like mobile cranes or piling machines. The costs for hiring these machines are often very high and they are usually scheduled within different projects. In consequence, significant postponing of operation times is sometimes not possible or additional suppliers need to be contracted. These restrictions can also be modeled by time windows. Activities that require special temporal

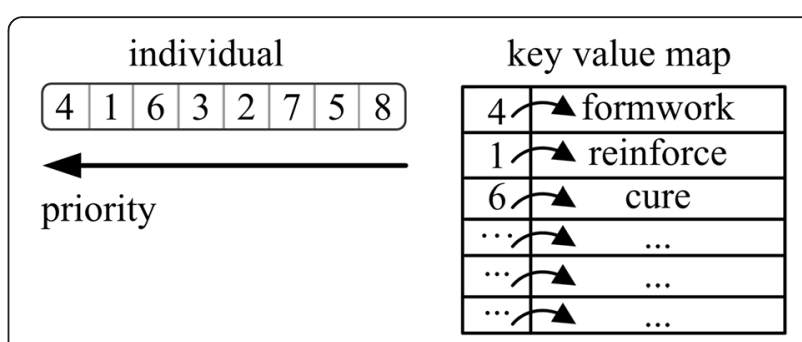

Fig. 7 Example of an individual's chromosome that encode a prioritized activity list 


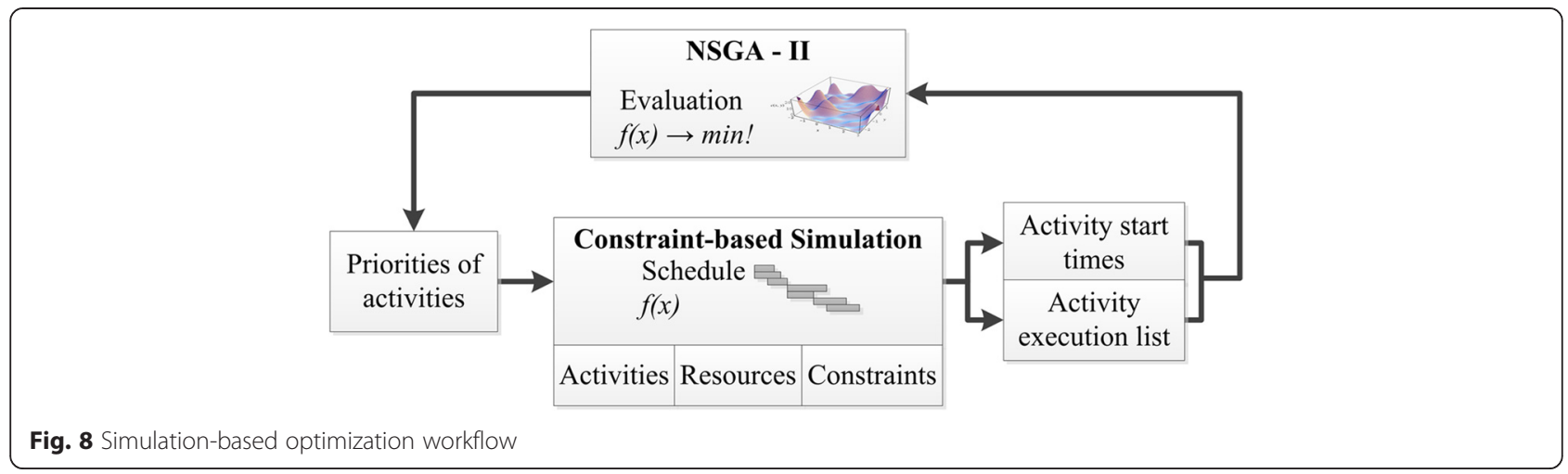

equipment should be scheduled within the bounds of the time windows.

\section{Established sequences}

Construction activities are often scheduled several times in the same order, in particular, in the context of highrise buildings with similar structure. That means for each level the same types of activities are defined in the target schedule. One aim is to enable learning effects to increase the performance and the resulting quality. In consequence, the established sequences should not be changed in the scope of the adaptation. Established sequences can be considered by using weighted constraints. Thereby, the violation costs are calculated based on the distance between the activities of a certain sequence compared to the target sequence.

\section{Milestones}

Milestones are important events for clients and contractors. A milestone is often put at the end of a stage to mark the completion of a work package or phase. Furthermore, payments are often associated with reaching certain milestones. Therefore, another goal is to keep the defined milestones or not to exceed them significantly. Milestones are modeled as k-weighted constraints. Violation costs occur if the milestone date is exceeded by a certain time.

\section{Additional resources}

If the current delays are significant or the target schedule is very ambitious, it is sometimes not possible to fulfill the additional target schedule constraints or the general project goals. In this case, two strategies can be pursued. One possibility is to release certain constraints. Another way is to define additional resources or reallocate specific resources. Additional resources can be integrated by increasing the amount of or extending the shifts of critical resources for a certain period. For example, the daily shift can be extended by two hours or the contractors can order weekend shifts. Reallocation means in this context that more resources are scheduled to perform a certain

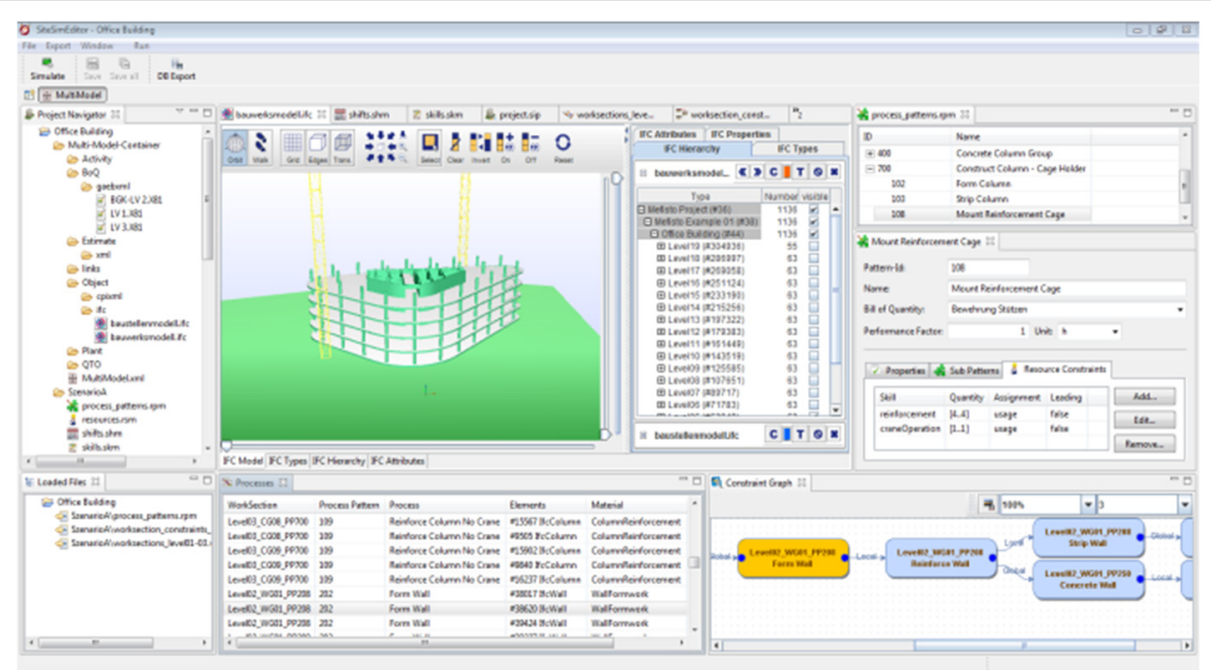

Fig. 9 The SiteSimEditor to prepare input data for construction simulation 
Table 1 Activity data of the project

\begin{tabular}{|c|c|c|c|c|c|}
\hline Activity ID & Description & Execution Mode & Duration (days) & Predecessor & Resource requirement \\
\hline 1 & Mobilization and site facilities & 1 & 25 & - & 2 worker \\
\hline 2 & Soiltest & 1 & 11 & - & 2 worker \\
\hline \multirow[t]{3}{*}{3} & \multirow[t]{3}{*}{ Excavation work } & 1 & 21 & 1 & 4 worker \\
\hline & & 2 & 17 & 1 & 5 worker \\
\hline & & 3 & 14 & 1 & 6 worker \\
\hline \multirow[t]{2}{*}{4} & \multirow[t]{2}{*}{ Piling work } & 1 & 20 & 1 & 5 worker \\
\hline & & 2 & 17 & 1 & 6 worker \\
\hline 5 & Pile loading test & 1 & 15 & 2 & 2 worker \\
\hline \multirow[t]{3}{*}{6} & \multirow[t]{3}{*}{ Backfilling and M\&E work } & 1 & 9 & 4 & 3 worker \\
\hline & & 2 & 7 & 4 & 4 worker \\
\hline & & 3 & 6 & 4 & 5 worker \\
\hline \multirow[t]{3}{*}{7} & \multirow[t]{3}{*}{ Pile cap work } & 1 & 14 & 2,4 & 4 worker \\
\hline & & 2 & 11 & 2,4 & 5 worker \\
\hline & & 3 & 9 & 2,4 & 6 worker \\
\hline 8 & Column rebar and M\&E work & 1 & 10 & 5 & 5 worker \\
\hline \multirow[t]{4}{*}{9} & \multirow[t]{4}{*}{ Slab casting } & \multirow[t]{2}{*}{1} & \multirow[t]{2}{*}{12} & \multirow[t]{2}{*}{$3,6,7$} & 5 worker \\
\hline & & & & & 1 mobile crane \\
\hline & & \multirow[t]{2}{*}{2} & \multirow[t]{2}{*}{10} & \multirow[t]{2}{*}{$3,6,7$} & 6 worker \\
\hline & & & & & 1 mobile crane \\
\hline 10 & Column formwork & 1 & 10 & 8 & 4 worker \\
\hline 11 & Roof beam and slab formwork & 1 & 12 & 9 & 5 worker \\
\hline \multirow[t]{2}{*}{12} & \multirow[t]{2}{*}{ Column casting } & \multirow[t]{2}{*}{1} & \multirow[t]{2}{*}{10} & \multirow[t]{2}{*}{9} & 4 worker \\
\hline & & & & & 1 mobile crane \\
\hline 13 & Roof beam and slab rebar & 1 & 10 & 11,12 & 5 worker \\
\hline \multirow[t]{2}{*}{14} & \multirow[t]{2}{*}{ Roof parapet wall casting } & \multirow[t]{2}{*}{1} & 14 & 12 & 5 worker \\
\hline & & & & & 1 mobile crane \\
\hline 15 & M\&E work 1 & 1 & 7 & 12 & 4 worker \\
\hline 16 & Door and window frame & 1 & 7 & 14 & 3 worker \\
\hline 17 & M\&E work 2 & 1 & 7 & 13,14 & 4 worker \\
\hline 18 & Roof slab casting & 1 & 12 & 15 & 4 worker \\
\hline & & & & & 1 mobile crane \\
\hline & & 2 & 10 & 15 & 5 worker \\
\hline & & & & & 1 mobile crane \\
\hline & & 3 & 8 & 15 & 6 worker \\
\hline & & & & & 1 mobile crane \\
\hline 19 & Plastering work & 1 & 10 & 16,17 & 4 worker \\
\hline 20 & Brick wall laying & 1 & 14 & 18 & 4 worker \\
\hline & & 2 & 11 & 18 & 5 worker \\
\hline & & 3 & 10 & 18 & 6 worker \\
\hline 21 & Ceiling skimming work & 1 & 7 & 11 & 4 worker \\
\hline 22 & Toilet floor and wall tiling work & 1 & 14 & 20 & 3 worker \\
\hline & & 2 & 11 & 20 & 4 worker \\
\hline & & 3 & 8 & 20 & 5 worker \\
\hline 23 & Drain work & 1 & 10 & 19,21 & 4 worker \\
\hline
\end{tabular}


Table 1 Activity data of the project (Continued)

\begin{tabular}{llllll}
\hline 24 & Apron slab casting & 1 & 9 & 21 & 5 worker \\
25 & Door and window & 1 & 7 & 22 & 5 worker \\
26 & Painting work & 1 & 14 & 17,22 & 4 worker \\
27 & Fencing work & 1 & 16 & 24 & 5 worker \\
28 & External wall plastering & 1 & 10 & 25 & 4 worker \\
& & 2 & 8 & 25 & 5 worker \\
29 & Electrical final fix & 1 & 6 & 25 & 2 worker \\
30 & Main gate installation & 1 & 3 & 29 & 3 worker \\
31 & External wall painting & 1 & 12 & 27,30 & 4 worker \\
32 & Qualified person inspection & 1 & 5 & 28,31 & 2 worker \\
34 & Landscape work & 1 & 10 & 32,33 & 1 worker \\
35 & Registered inspector inspection & 1 & 7 & 34 & 1 worker \\
37 & Authority inspection & 1 & 1 & 35 & 1 worker \\
\hline
\end{tabular}

activity to reduce the execution time. However, this is only useful in certain cases.

\section{Simulation-based adaption}

The adaption of a target schedule is based on searching for a feasible solution. For this, the additional constraints and the uncertain actual logistics data, including the previously calculated delays for each activity, must be considered. The previously calculated activity's mean delays are considered as temporal constraints. In general, this problem is called a constraint satisfaction problem. Due to the fact that not only hard constraints, but also soft constraints and general project goals, such as project duration, costs and quality need to be considered, it is advisable to apply some kind of optimization strategy in order to find a good solution for the constraint satisfaction problem. In this case, a good solution is a schedule which fulfills all hard constraints and minimizes the constraint violation costs. As mentioned before, in this research a scheduling problem is represented by a complex constraint-based simulation model. Metaheuristic optimization approaches are often applied to orchestrate the simulation model in such a way that the resulting schedule is an optimal or near-optimal solution of the constraint satisfaction problem.

In this paper, an evolutionary algorithm is coupled with a constraint-based discrete-event simulation to generate feasible schedules based on priority lists. For this, the NSGA-II algorithm is applied. This evolutionary algorithm is chosen due to its advantageous ability to conduct multi-objective optimization and because it outperforms other existing multi-objective evolutionary algorithms (Deb et al. 2002). The individual's chromosomes are defined as an activity list. This list is used to generate construction schedules. The length of each individual corresponds to the number of activities that have to be scheduled. Each activity is modeled by a unique key value. The first key value entry in each chromosome represents the modeled activity that should be scheduled first. The last chromosome key value entry represents another activity that should be scheduled as the last activity. Thus, the order of key values within a chromosome represents the execution sequence of the activities modeled by the key values (cf. Fig. 7).

However, every individual is evaluated by utilizing the constrained-based discrete-event simulation. Proceeding this way, the constrained-based discrete-event simulation performs as a repair mechanism to the evolutionary algorithm. Furthermore, all constraints are handled by the simulation. The application of the constraint-based simulation approach enables the utilization of discrete-event simulation for the generation of valid construction schedules that neither violate precedence nor resource constraints (Beißert et al. 2007). The main input parameter for the constraint-based discrete-event simulation is the list of construction activities. This list corresponds to the evolutionary algorithm individual's chromosome. The activity list is interpreted as a priority list in which the first entry of the chromosome is the activity with the highest priority. During the simulation, the activity with the highest priority is always checked for execution. Supposing the activity with the highest priority is not executable due to non-fulfilled precedence or resource constraints, the activity with the second highest priority is checked for its execution ability and so on. The workflow of NSGA-II with the discrete-event simulation coupling is depicted in Fig. 8. 


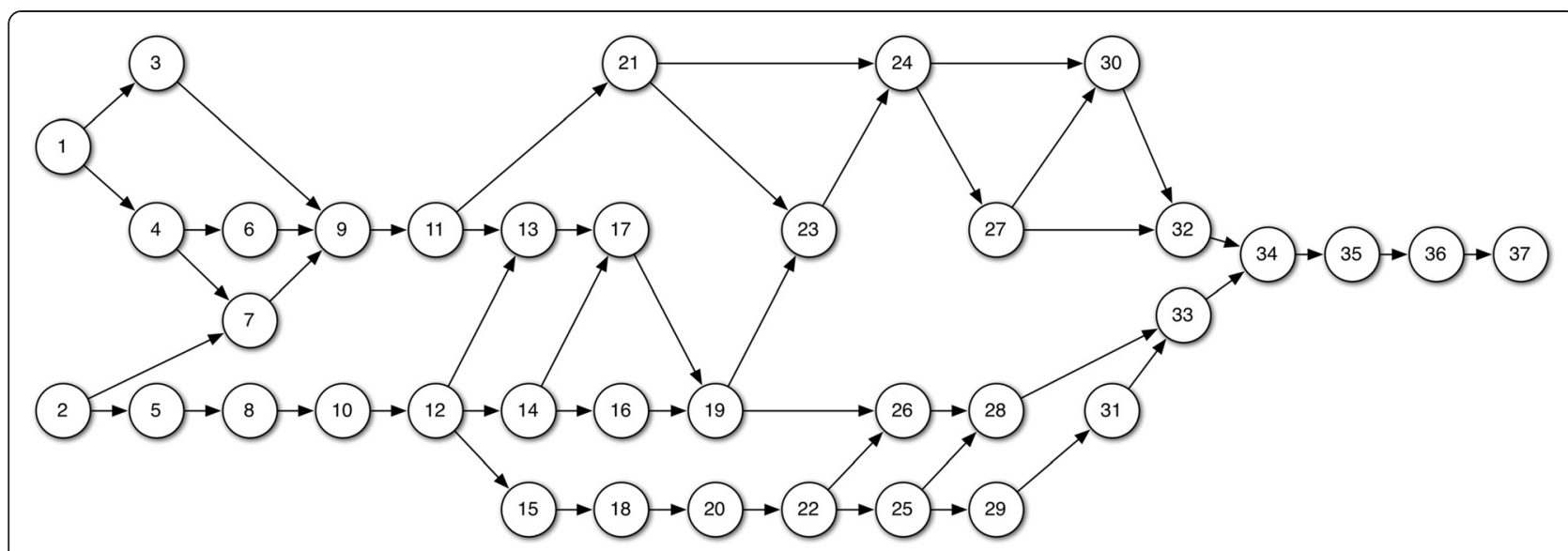

Fig. 10 Graph representation of the construction project with emphasis on precedence relationships between activities

\section{Implementation}

As already mentioned, one main benefit of the constraintbased construction simulation is that additional constraints can be easily integrated into an existing simulation model. However, defining a realistic and highly detailed simulation model for construction scheduling can be very time-consuming. Due to this fact, a user-friendly software tool has been developed to speed-up the simulation definition process. The so-called SiteSimEditor is a BIM-based tool to prepare input data for construction simulation (cf. Fig. 9). The SiteSimEditor can be used free of charge for non-commercial research projects (SimPlan 2015).

By importing available project information like 3D building models, construction site layouts, bill of quantities and quantity take-off items, the construction activities and various constraints can be specified interactively. To keep the expenditure of time for data preparation as low as possible, reusable templates have been developed. Currently, several templates for activities, resources, technology dependencies, strategic executions sequences, and working shifts are available. Based on the prepared and generated input data simulation experiments can be directly executed by using the SiteSimEditor. These simulation experiments are performed by a constraint-based discrete-event simulation engine, which is implemented as a component of the SiteSimEditor. Afterwards, the results can be imported and visualized as Gantt charts, 4D animations or in form of different diagrams.

The SiteSimEditor has been extended to integrate target schedule constraints. For defining delivery dates and temporal equipment, an existing availability and shift management plugin can be used. In general, for each resource different partially overlapping shifts, which can be associated with duration limits, can be specified and considered within the simulation model. New components and user-interfaces have been developed to define constraints such as milestones or established sequences.
However, information about upper bounds or sequences between activities must be specified manually. Other important aspects are the definition of additional resources and modified shifts to relax existing constraints. In many cases, this has to be performed to find a realistic adaption of the target schedule and to satisfy constraints like milestones or project duration.

\section{Results and discussion}

In order to demonstrate the proposed approach a case study is adapted from literature. This case study is based on a simplified warehouse construction project introduced by Chen and Weng (2009). The project comprises of a total of 37 construction activities, 48 precedence constraints, and 41 resource constraints. Furthermore, nine activities can be executed in various execution modes, so that this construction project scheduling results in a MRCPSP. A more detailed description of the construction activities including their resource requirements are given in Table 1. In addition, Fig. 10 depicts a graph representation of the project, such that prevalent precedence relationships are easily visible. The project is realized with a maximum of 12 labor resources each day. Additionally, an adaption has been made in order to

Table 2 Applied parameters for target schedule generation as well as actual schedule adaption

\begin{tabular}{ll}
\hline Parameter & Value \\
\hline population size & 50 \\
termination criterion & crowding distance deviation \\
crossover operator & single point crossover by Hartmann \\
probability & 1.0 \\
mutation operator & swap mutation \\
probability & $1 / 37$ \\
selection operator & binary tournament \\
\hline
\end{tabular}




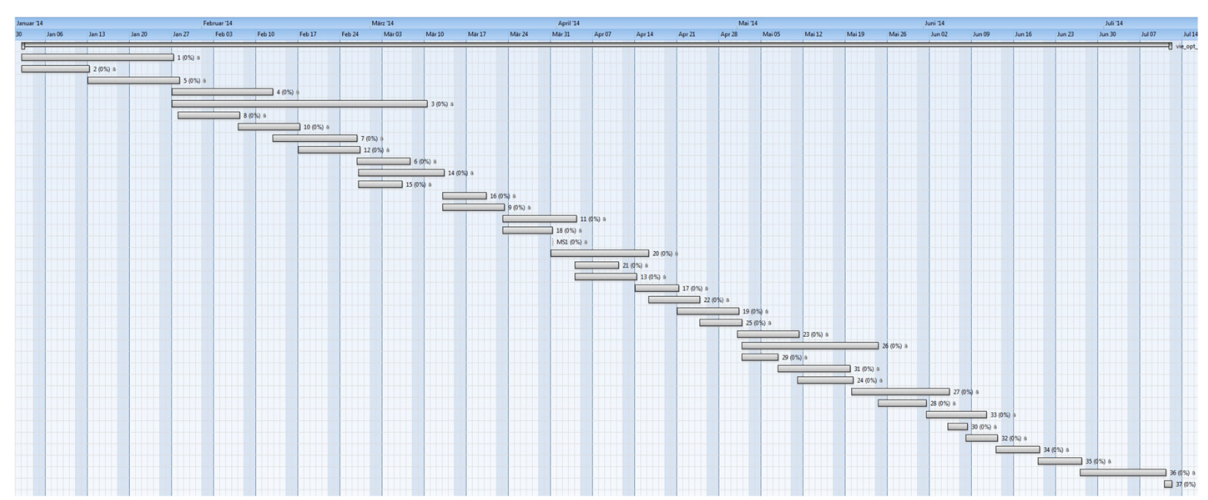

Fig. 11 Target schedule for the warehouse construction project as Gantt chart Representation

support a mobile crane for casting activities. The mobile crane is available only for a limited time, so that only the casting activities can make use of it. The initial project costs are $600 \$$ per day, and $100 \$$ per day per labor resource. During the contracted period the mobile crane costs $162 \$$ per hour. Eight hours per day are applied as working shifts. Another important extension is an additional milestone. It marks the point in time when all casting activities must be finished. Further adaptions to the case study are two modified precedence relationships. As opposed to the original research work in Chen and Weng (2009), the precedence relationship between activity 9 (slab casting) and activity 12 (column casting) was replaced. The replacement is a precedence relationship between activity 10 (column formwork) and activity 12 (column casting). Then, the other modification introduces a new precedence relationship between activity 23 (drain work) and activity 24 (apron slab casting). This relation did not exist before. These modifications are consistent with the research work by Cheng et al. (2014).

In order to generate a target schedule, discrete-event simulation-based optimization is applied. For this, the NSGA-II optimization method is utilized. The applied configuration values are given in Table 2 . The generated target schedule has a make-span of 190 days, which is equal to the results presented in Cheng et al. (2014) (cf. Fig. 11). The total costs of the generated target schedule are $392,712 \$$. The following study is based on this target schedule.

\section{Integration of actual logistics data}

In order to demonstrate the proposed reactive construction scheduling approach, additional availability of actual logistics data is introduced. These actual logistics data contain information about the delivery status of required material. The assumption is that on day 40 of the project execution, new actual data is available. These data report a delay of two material deliveries. One material delivery is required by activity 7 , the other one is required by activity 10. These delays of the required material are given by the vague assessment "The delay will be approximately between 4 to 6 days". According to the second step of the approach, these imprecise assessments need to be prepared. The vague assessment "approximately between 4 to 6 days" is modeled by a fuzzy set (cf. Fig. 12).

Since both delays are equal, the same fuzzy set applies for each delay. These sets need to be integrated into the target schedule, allowing generation of an actual schedule based on actual logistics data. For this, a sensitivity analysis based on the $\alpha$-cut method is utilized. Given the fact that the responsible construction manager is not confident of the assessment, the $\alpha$-cut value of 0.5 is selected. For every set and every interval 50 unique samples are derived, thus in total 300 samples for each set. Then, 300 simulation experiments are performed to analyze the impact of the delays. For each experiment, one sample for each fuzzy set is integrated into the existing target simulation model. Each sample is implemented as a temporal constraint for activity 7 and activity 10, respectively. Because of that, the corresponding activities may not be scheduled before the given temporal constraint is satisfied. The result of this analysis is

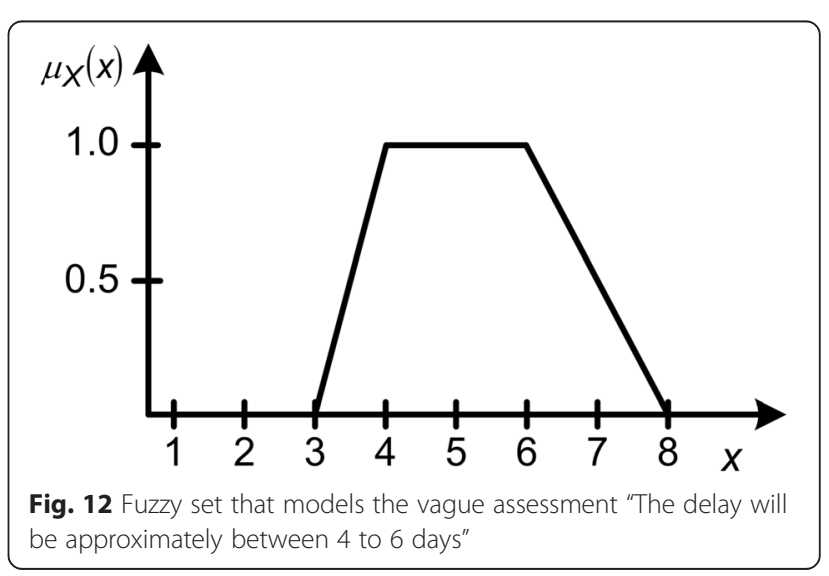



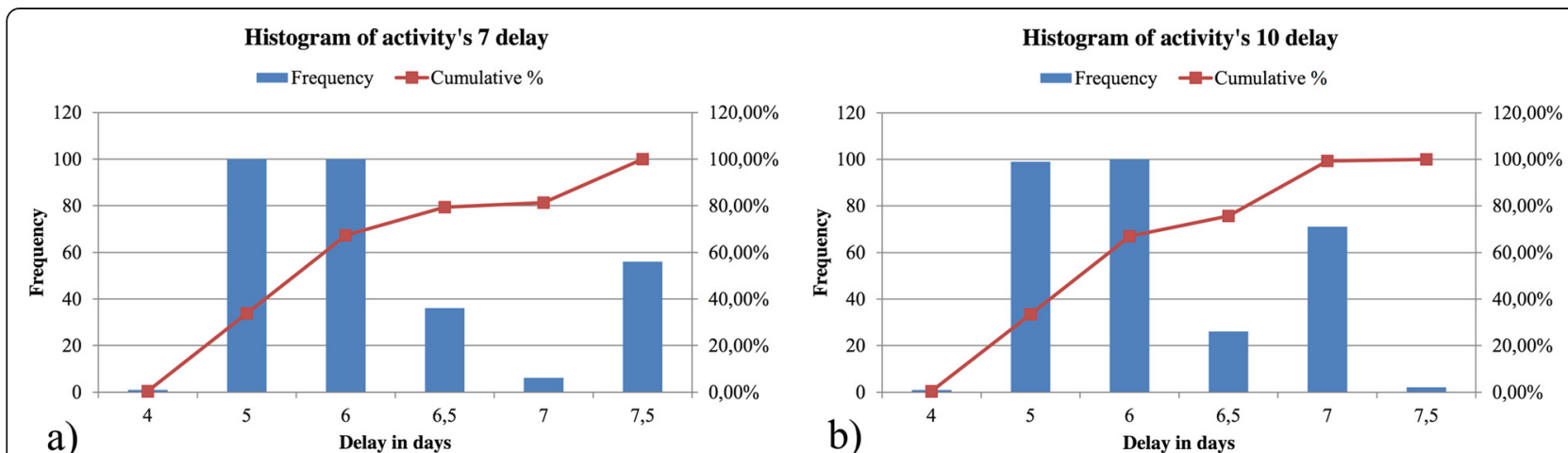

Fig. 13 The frequency of occurrence and cumulative percentage of the delay of activity 7 (a) and activity 10 (b), respectively

the actual schedule. Figs. 13, 14 and 15 depict results that are more detailed.

Figure 13 shows the histograms including frequency of occurrence and cumulative percentages of delay for activity 7 (cf. Fig. 13a) and activity 10 (cf. Fig. 13b). It is obvious that both activities will likely be delayed by at least six days. Thus, their tardiness has an impact on subsequent activities. Figure 14 shows in detail the delay of the additionally included milestone. Here, it is obvious that the milestone cannot be achieved within the previously scheduled period. The milestone will be likely delayed by three days, such that the mobile crane is not available when required. Figure 15 depicts an excerpt of the Gantt chart of the calculated actual schedule. It includes all concerned activities with calculated mean delays.

\section{Target actual-comparison}

In the third step the target-actual comparison is performed. Here each activity is controlled for timeliness. However, in the given study an extensive evaluation is not compulsory. This is because of the milestone's evaluation. As already revealed in Fig. 12, the milestone exceeds its contracted deadline very likely by three days. As consequence, the mobile crane is not disposable and therefore activity 18 cannot be finished, such that the complete construction project remains not accomplishable. Thus, the target-actual comparison demands an adaption of the actual schedule.

\section{Adjustment of actual schedule}

This last step performs a simulation-based optimization to adapt the actual schedule. During the reactive rescheduling, some constraints were relaxed. The daily shift of the labor resources is extended by two hours. Each overtime hour causes a cost increase by $20.0 \$ / \mathrm{h}$ per labor resource. Furthermore, the required mobile crane is also available on the subsequent days. The relaxation of the mobile crane's availability is modeled as a k-weighted constraint. If the mobile crane is assigned on another day not contracted, additional costs occur. On additional days, the costs increase to $200 \$$ per hour. However, some additional constraints are defined. These additional constraints are date delivery constraints that are modeled as time windows. These constraints serve the purpose that adaption of the planned target schedule should be as little as possible but as much as required. Time windows parameters for these constraints are based on the calculated mean delay values as calculated by the sensitivity analysis in step 2.

The optimization compromises the variation of activity sequences and resource allocation considering two main objectives: observance of the milestone and minimizing the total resource costs of workers and the mobile crane. Four simulation experiments were performed by combining the shift and mobile crane extension (cf. Table 3).

The optimization results of the experiments Exp3 and Exp4 are shown in Table 4. As comparison, the last column contains data for the case before re-scheduling was required. The observance of the milestone cannot be fulfilled by the first two experiments. The experiments Exp3 and Exp4 differ regarding the costs due to the shift and mobile crane extension, also the remaining project duration is slightly different. However, both schedule

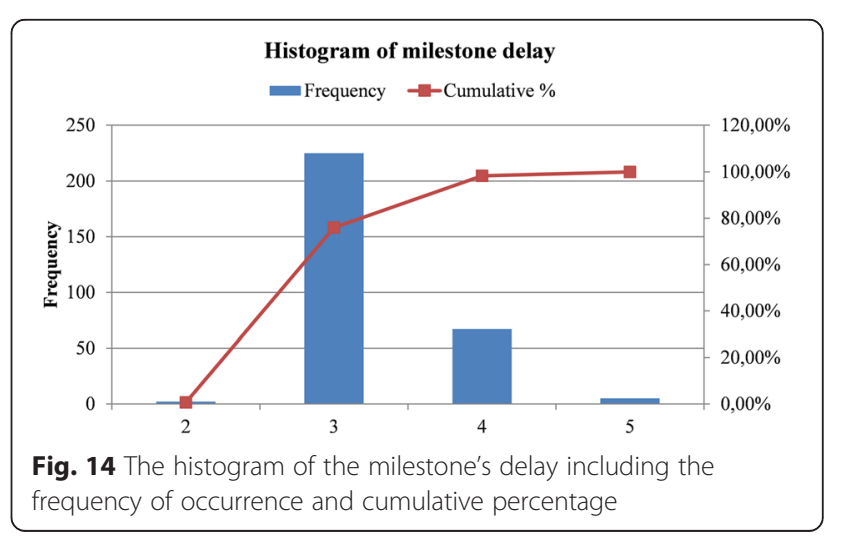




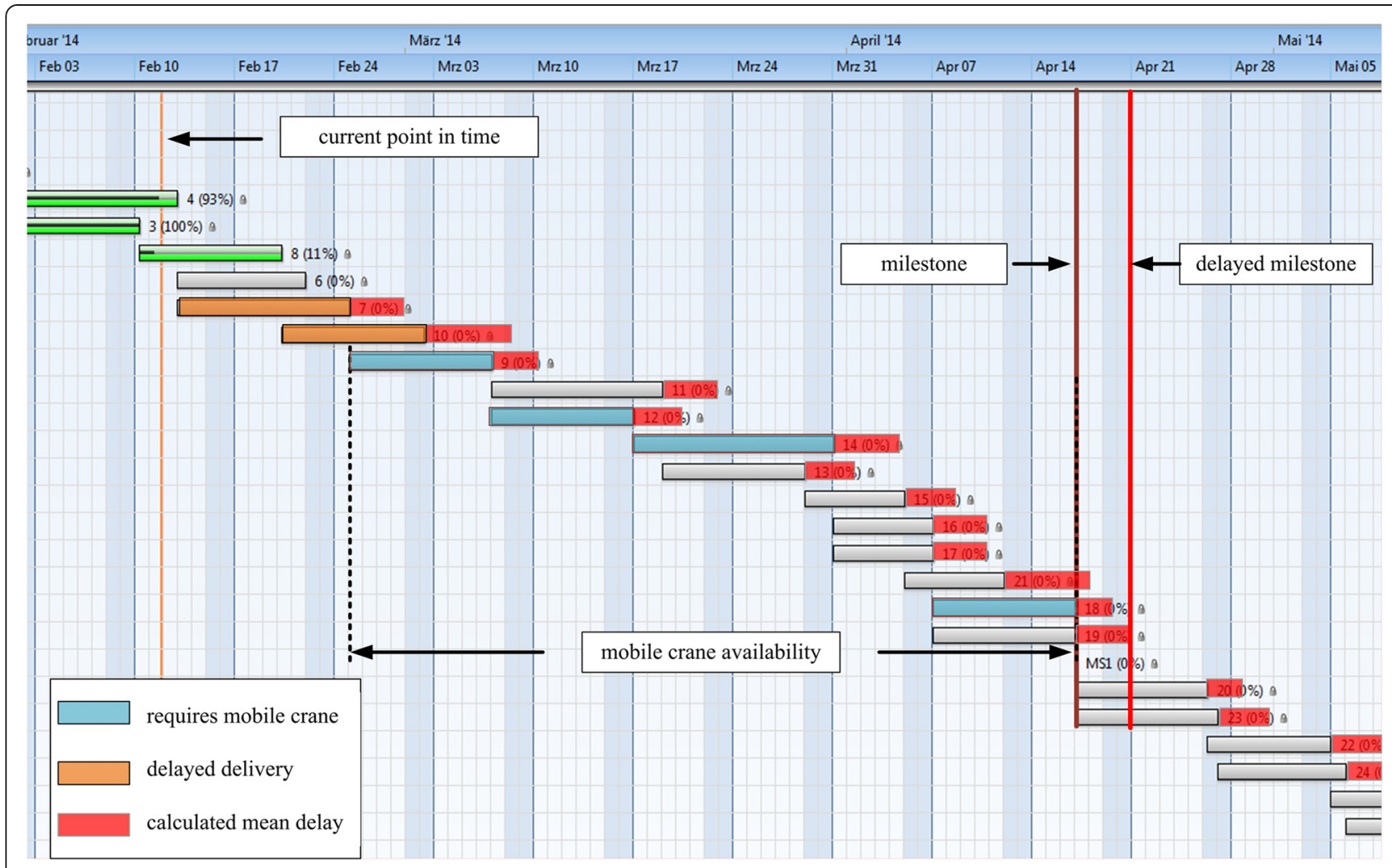

Fig. 15 Actual schedule excerpt with activity delays, mobile crane requirements, and project milestone

adaptions are possible. In the next step, the project manager needs to decide which adaption is most suitable.

\section{Conclusions}

The adaption of construction schedules based on current logistics data is an important aspect in the context of efficient project execution. Such current data can reveal disruptions in construction logistic processes, e.g. delayed material delivery or machine breakdowns among others. However, current logistics data is fraught with uncertainty, due to infrequent acquisition or inaccurate duration between recordings. Therefore, a reactive construction scheduling approach, which is composed of multiple parts, is presented. For one, the approach enables the processing of uncertain current logistics data, in order to investigate their impacts on the planned target schedule. A constraint-based simulation analysis is performed that considers the current logistics data, which

Table 3 Simulation experiments for schedule adaption

\begin{tabular}{lll}
\hline Experiment & Shift extension & Crane extension \\
\hline Exp1 & - & - \\
Exp2 & $X$ & - \\
Exp3 & - & $x$ \\
Exp4 & $X$ & $x$ \\
\hline
\end{tabular}

results in an actual, updated schedule. Furthermore, a target-actual comparison is utilized to identify deviations between the planned target schedule and the actual schedule. Based on the comparison results, a simulationbased optimization is performed with the objective to minimize the deviations between the planned and actual schedule. This paper particularly emphasizes the simulation-based optimization of target schedules. In order to adapt the target schedule, information regarding this schedule can be modeled by additional soft constraints. Various target schedule constraints are classified and modeled. By considering these additional constraints in the simulation model, an efficiently adapted

Table 4 Simulation experiments for schedule adaption on day 40

\begin{tabular}{llll}
\hline & Exp3 & Exp4 & $\begin{array}{l}\text { Infeasible Target } \\
\text { Schedule }\end{array}$ \\
\hline Remaining duration in days & 161 & 158 & 152 \\
Costs (fix) in \$ & 96,600 & 94,800 & \\
Costs (labor) in \$ & 104,220 & 104,172 & 106,752 \\
Costs (crane) in \$ & 167,184 & 167,184 & 167,184 \\
Costs (shift extension) in \$ & 0 & 18,480 & 0 \\
Costs (crane extension) in \$ & 13,000 & 4,200 & 0 \\
Total costs in \$ & 381,004 & 388,836 & 365,136 \\
\hline
\end{tabular}


schedule can be calculated. To perform the simulationbased optimization, the NSGA II algorithm is utilized. The concept was verified by applying an established use case. The presented results show that solutions found by utilizing the reactive construction scheduling approach can be applied to support project execution. Findings in the conducted case study are that the simulation-based analysis is capable of identifying whether logistic related disruptions compromise a successful project realization. Furthermore, it has been shown that optimal solutions can be found which fulfill all hard constraints and additional target schedule restrictions.

Still further research is required, such as modifying the definition of additional target schedule constraints. This paper already mentions some, but for various construction projects in different domains, like mechanized tunneling or transport infrastructure constructions other constraints could be necessary. Furthermore, stochastic optimization will be integrated to find adaptions that are both robust and reliable. Such a robust adaption should protect the adapted schedule against further disruptions as much as possible. Another optimization related aspect is to consider alternative activities for disrupted activities. For example, when it is not possible to realize column work with prefabricated elements, then consider whether in-situ work is adequate as a substitution. Another important aspect is the availability of current logistic data. Additional research work is required to improve the availability and accuracy of current data for construction management. A better availability of data allows the application of different methods to cope with uncertainty, i.e. portability-based approaches could be applied to investigate the impact of logistic related disturbances. Of course, more accurate current data improves the assessment of uncertainty. Possible research into a different adaption method could include knowledge-based approaches. However such approaches require a knowledge base with possible adaption or substitution rules for disrupted activities.

\section{Competing interests}

The authors declare that they have no competing interests.

\section{Authors' contributions}

Both authors contributed extensively to the work presented in this paper. Szczesny reviewed and analyzed the literature, conducted the case study, and drafted the manuscript. König supervised the entire processes of this study, and edited the manuscript. All authors read and approved the final manuscript.

Received: 2 December 2014 Accepted: 6 February 2015

Published online: 28 March 2015

\section{References}

Abebe, A, Guinot, V, \& Solomatine, D. (2000). Fuzzy alpha-cut vs. Monte Carlo techniques in assessing uncertainty in model parameters. Proc. 4th International Conference on Hydroinformatics, 23-27 July 2000. lowa City, USA: University of lowa College of Engineering.
AbouRizk, S. (2010). Role of simulation in construction engineering and management. Journal of Construction Engineering and Management, 136(10), 1140-1153. doi:10.1061/(ASCE)CO.1943-7862.000022.

Beißert, U, König, M, Bargstädt, H-J. (2007). Constraint-based simulation of outfitting processes in building engineering. Proc. 24th Int. Conf. Manag. IT Constr. CIB W078, 26-29 June 2007. Maribor, Slovenia. http://itc.scix.net/cgi-bin/works/ Show?w78_2007_95.

Buckley, J, \& Eslami, E. (2002). An Introduction to Fuzzy Logic and Fuzzy Sets. Heidelberg: Physika-Verlag.

Cai, H, Andoh, AR, Su, X, \& Li, S. (2014). A boundary condition based algorithm for locating construction site objects using RFID and GPS. Advanced Engineering Informatics, 28(4), 455-468. doi:10.1016/j.aei.2014.07.002.

Chen, P-H, \& Weng, H. (2009). A two-phase GA model for resource-constrained project scheduling. Automation in Construction, 18(4), 485-498.

Cheng, MY, Tran, DH, \& Wu, YW. (2014). Using a fuzzy clustering chaotic-based differential evolution with serial method to solve resource-constrained project scheduling problems. Automation in Construction, 37, 88-97.

Cho, CY, Kwon, S, Shin, TH, Chin, S, \& Kim, YS. (2011). A development of next generation intelligent construction liftcar toolkit for vertical material movement management. Automation in Construction, 20(1), 14-27. doi:10.1016/j.autcon.2010.07.008.

Deb, K, Pratap, A, Agarwal, S, \& Meyarivan, T. (2002). A fast and elitist multiobjective genetic algorithm: NSGA-II. IEEE Transactions on Evolutionary Computation, 6(2), 182-197. doi:10.1109/4235.996017.

Dzeng, R-J, Lin, C-W, \& Hsiao, F-Y. (2014). Application of RFID tracking to the optimization of function-space assignment in buildings. Automation in Construction, 40, 68-83. doi:10.1016/j.autcon.2013.12.011.

Ergen, E, Akinci, B, \& Sacks, R. (2007). Tracking and locating components in a precast storage yard utilizing radio frequency identification technology and GPS. Automation in Construction, 16((3), 354-367. doi:10.1016/ j.autcon.2006.07.004.

Esthehardian, E, Afshar, A, \& Abbasnia, R. (2009). Fuzzy-based MOGA approach to stochastic time-cost trade-off problem. Automation in Construction, 18(5), 692-701. doi:10.1016/j.autcon.2009.02.001

Ghoddousi, P, Eshtehardian, E, Jooybanpour, S, \& Javanmardi, A. (2013). Multi-mode resource-constrained discrete time-cost-resource optimization in project scheduling using non-dominated sorting genetic algorithm. Automation in Construction, 30, 216-227. doi:10.1016/j.autcon.2012.11.014.

Hajjar, D, \& AbouRizk, S. (1999). Simphony: an environment for building special purpose construction simulation tools. 1999 Winter Simulation Conference Proceedings (pp. 998-1006). AZ, USA: Phoenix. doi:10.1109/WSC.1999.816811.

Halpin, D. (1977). Cyclone - method for modeling job site processes. Journal of the Construction Division, 103(3), 489-499.

Hanss, M. (2005). Applied Fuzzy Arithmetic - An Introduction with Engineering Applications. Berlin: Springer.

Hartmann, S, \& Kolisch, R. (2006). Experimental investigation of heuristics for resource-constrained project scheduling: An update. European Journal of Operational Research, 174(1), 23-37. doi:10.1016/j.ejor.2005.01.065.

Hotz, I, Hanisch, A, Schulze, T. (2006). Simulations-based early warning systems as a practical approach for the automotive industry. Proceedings of the 2006 Winter Simulation Conference, 1962-1970, 3-6 Dec 2006. Monterey, CA, USA. doi:10.1109/WSC.2006.322981.

Kim, C, Ju, Y, Kim, H, \& Kim, JH. (2009). Resource Management in Civil Construction Using RFID Technologies. 26th International Symposium on Automation and Robotics in Construction (ISARC 2009) (pp. 105-108). Austin, TX, USA: IAARC.

Koo, B, Fischer, M, \& Kunz, J. (2007). A formal identification and re-scheduling process for developing sequencing alternatives in CPM schedules. Automation in Construction, 17(1), 75-89. doi:10.1016/j.autcon.2007.03.005.

Kulejewski, J. (2011). Construction project scheduling with imprecisely defined Constraints. In H Wamelink, R Geraedts, \& L Volker (Eds.), Proceedings of the CIB International Conference Management and Innovation for a Sustainable Build Environment. Amsterdam, Netherlands: Delft: University of Technology.

Leu, SS, \& Yang, CH. (1999). A genetic-algorithm-based resource-constrained construction scheduling system. Construction Management and Economics, 17(6), 767-776. doi:10.1080/014461999371105.

Liao, TW, Egbelu, PJ, Sarker, BR, \& Leu, SS. (2011). Metaheuristics for project and construction management - A state-of-the-art review. Automation in Construction, 20(5), 491-505. doi:10.1016/j.autcon.2010.12.006.

Liu, SS, \& Shih, KC. (2009). Construction rescheduling based on manufacturing rescheduling framework. Automation in Construction, 18(6), 715-723. doi:10.1016/j.autcon.2009.02.002. 
Martinez, J. (1998). EarthMover-simulation tool for earthwork planning. Proceedings of the 1998 Winter Simulation Conference, 1263-1271, 13-16 Dec 1998. Washington, DC, USA. doi:10.1109/WSC.1998.745988.

Martinez, J, \& loannou, P. (1994). General purpose simulation with Stroboscope. Winter Simulation Conference Proceedings, 1159-1166, 11-14 Dec 1994. Orlando, FL, USA. doi:10.1109/WSC.1994.717503.

Montaser, A, \& Moselhi, O. (2014). RFID indoor identification for construction projects. Automation in Construction, 39, 167-179. doi:10.1016/ j.autcon.2013.06.012.

Ren, Z, Anumba, C, \& Tah, J. (2011). RFID-facilitated construction materials management (RFID-CMM) - A case study of water-supply project. Advanced Engineering Informatics, 25(2), 198-207. doi:10.1016/j.aei.2010.02.002.

Ruwanpura, J, \& AbouRizk, S. (2001). Design, development and application of soil transition algorithms for tunneling using special purpose simulation. Proceedings of the 2001 Winter Simulation Conference, 1512-1520, 9-12 Dec 2001. Washington, DC, USA. doi:10.1109/WSC.2001.977479.

Said, H, \& El-Rayes, K. (2014). Automated multi-objective construction logistics optimization system. Automation in Construction, 43, 110-122. doi:10.1016/j.autcon.2014.03.017.

Simplan AG (2015). SiteSim-Editor - Construction work scheduling http://simplan.de/ en/software/ergaenzende-produkte/sitesim.html. Accessed 3 Feb 2015.

Song, L, \& Eldin, N. (2012). Adaptive real-time tracking and simulation of heavy construction operations for look-ahead scheduling. Automation in Construction, 27, 32-39. doi:10.1016/j.autcon.2012.05.007.

Wang, L-C, Lin, Y-C, \& Lin, PH. (2007). Dynamic mobile RFID-based supply chain control and management system in construction. Advanced Engineering Informatics, 21(4), 377-390. doi:10.1016/j.aei.2006.09.003.

Wu, IC, Borrmann, A, Beißert, U, König, M, \& Rank, E. (2010). Bridge construction schedule generation with pattern-based construction. Advanced Engineering Informatics, 24(4), 379-388. doi:10.1016/j.aei.2010.07.002.

Xu, J, AbouRizk, S, \& Frazer, C. (2003). Integrated three-dimensional computeraided design and discrete-event simulation models. Canadian Journal of Civil Engineering, 30((2), 449-459. doi:10.1139//02-110.

Yin, S, Tserng, H, Wang, J, \& Tsai, S. (2009). Developing a precast production management system using RFID technology. Automation in Construction, 18((5), 677-691.

Zadeh, L. (1965). Fuzzy sets. Information and Control, 3, 338-353.

Zhang, C, \& Arditi, D. (2013). Automated progress control using laster scanning technology. Automation in Construction, 36, 108-116. doi:10.1016/j.autcon.2013.08.012.

\section{Submit your manuscript to a SpringerOpen ${ }^{\circ}$ journal and benefit from:}

- Convenient online submission

- Rigorous peer review

- Immediate publication on acceptance

- Open access: articles freely available online

- High visibility within the field

- Retaining the copyright to your article

Submit your next manuscript at $>$ springeropen.com 